\title{
Eco-innovation and competitive strategy in global hotel chains: developing a conceptual relationship model
}

\author{
V. O. Menezes ${ }^{1} \&$ S. K. Cunha ${ }^{2}$ \\ ${ }^{1}$ Department of Tourism, Unicentro, Brazil \\ ${ }^{2}$ Business Management Ph.D. and Master Program, \\ Positivo University, Brazil
}

\begin{abstract}
The aim of this paper is to comprehend the relationship between eco-innovation and competitive strategies in global hotel chains. This is a qualitative and descriptive multiple case study with a cross-sectional time frame applying thematic content analysis. NVivo ${ }^{\circledR}$ software is used to analyse some of the data collected, based on triangulation of information. The data sources were empirical, gathered using interviews and questionnaires at three top global hotel chains that are specialists in sustainability in hospitality. Documents were also used as a source of data. The data indicated that there is a direct relationship between ecoinnovation and competitive strategies in global hotel chains. However, this relationship differs according to the case study in question. The relationship can be classified according to the biological conceptions of the relationship: parasitism, commensalism and mutualism (Saviotti, P.P. Co-evolution of technical, environmental and social system, 2010). Therefore, a conceptual model was drawn, presenting the variables related to these two phenomena.

Keywords: eco-innovation; competitive strategy, global hotel chains, relationship.
\end{abstract}

\section{Introduction}

According to Kirk [2], Bohdanowicz [3] and Bohdanowicz and Martinac [4], hotel companies are part of an industry that causes significant environmental impact. Aware of this situation, these companies have adopted practices and technologies to reduce the use of environmental resources. Despite the environmental issues, eco-innovations are also used to reduce costs and differentiate brands from their competitors. Therefore, these initiatives are also seen as competitive strategies [5, 
6]. The present study aims to comprehend the relationship between eco-innovation and competitive strategies in global hotel chains.

The study is justified theoretically, as it addresses a theme that has been the subject of few investigations in research on hospitality. Furthermore, it is discussed using a new approach that simultaneously examines innovation, from the viewpoint of systemic, evolutionary and socio-technical theories, sustainability and strategy.

This is a qualitative and descriptive multiple case study, applying a crosssectional time frame. The global chains have been defined as the focus of this research because these companies have more financial and organizational resources to invest in eco-innovations [7], meaning that they represent a larger universe of data on the research topics. In this study, global chains are conventionally understood as organizations that have a variety of hotel properties, with ownership, management and/or franchises located on at least two continents. Three global chains were chosen by a non-probabilistic sample. However, to maintain the confidentiality of the case studies, the companies are identified as Chain A, B, and C.

The data sources were empirical, gathered during interviews. However, documents were also used as a source of data. The interviews were conducted between February and March 2014 via Skype ${ }^{\circledR}$, and recorded with the prior consent of the respondents. The interview script was drawn from a semi-structured protocol forwarded to the professional in charge of issues related to the sustainability and strategy of the case studies. The script included ten open-ended and multiple-choice questions. The interview script was validated by content validity [8], in two stages. First, data related to these constructs were gathered through the existing theoretical framework. This was followed by expert validation from four randomly selected academics with considerable experience in research and publication on strategy, eco-innovation and sustainability in hospitability.

The analysis was conducted through a thematic content approach, using NVivo ${ }^{\circledR}$ software to analyse some of the data gathered, based on the triangulation of information to increase the reliability of the results. The data and analysis were presented in a descriptive report, in which also included tables, graphics and interview fragments to aid understanding of the conclusions.

The paper is divided into four sections. The introduction presents the main objective and the methodology. Section 2 discusses eco-innovation as a competitive strategy, showing and correlating different authors who study the subject. The third section describes the results and analyses, and the last section concludes the paper, bringing the study to a close and identifying the limitations of the investigation and suggestions for future research.

\section{Eco-innovation as competitive strategy}

Eco-innovation is defined by James [9] as the development of new products and processes that bring value to the customer and companies through a significant reduction in environmental impact. Andersen [10], adopting a similar position to 
James [9], defines eco-innovation as a type of innovation that is capable of generating income and reducing environmental impact, while creating value for organizations.

Porter and Van Der Linde [11] believe there is a relationship between ecoinnovation and the acquisition of competitive advantage. The authors explain that companies that deal with strict environmental regulations could increase their competitiveness, since they are encouraged to develop innovations that lead to greater efficiency through the redesign of products, processes and operation methods. The companies begin to use resources more consciously during the production phase, reducing waste and costs [11]. Moreover, many organizations have taken advantage of growing consumer interest in environmental issues and used innovation as a way of working with "green" products to enter new market segments $[11,12]$.

According to Porter [15], competitive advantage is a sustainable position achieved by the company to deal with the forces of competition in a particular market that allow it to overcome its rivals in long-term profitability. The acquisition of competitive advantages is the main goal of a corporate competitive strategy.

Based on Porter and Van Der Linde's approach [11, 13, 14], Eidat et al. [16] explain that the relationship between eco-innovation and organizational performance is based on several features, including the efficient use of inputs. This can generate cost savings for companies and lead companies to find new ways to turn waste into new products that provide additional revenue. It also offers the potential to reduce emissions below required levels, reducing the cost of compliance for organizations and helping them to improve their reputation as environmental leaders, given them an edge over their competitors.

Relating eco-innovation to the hospitality industry, Sloan et al. [5] describe the reasons that motivate hotels to invest in eco-innovation: potential cost savings; improved image and increased market share; acquisition of competitive advantage; intrinsic motivation, such as moral values, and increased motivation. Bohdanowicz and Martinac [4] found, from a survey of four major European hotel chains, that in addition to the factors mentioned by Sloan et al. [5], two other reasons motivate hoteliers to invest in eco-innovations: requests from guests and advice from other professionals.

The results show that that many of these motives lead to competitive advantages that are usually used as a competitive strategy by companies. Consequently, it might be concluded that there is a relationship between ecoinnovation and competitive strategies.

The concept of relationship came from Biology. According to Saviotti [1], a relationship is interaction between different populations. The author also explains that there are three types of relationship: parasitism, when one party clearly benefits from the other; commensalism, where one party benefits from another bringing harm, even if insignificant to the host, and mutualism, when both parties benefit from the exchange.

Regarding eco-innovations and competitive strategies, which are the focus of this study, it is suggested that the relationship between the two is one of mutualism 
because their relationship within the company is beneficial to both. This is one of the hypotheses proposed by authors such as Porter and Van Der Linde [11, 13, 14], and will be tested through empirical research.

\section{Results}

The following item shows part of the results obtained through interviews with three global hotel chains and document analyses.

Concerning motivates for investing in eco-innovation, the respondents chose the following alternatives, as shown in Table 1.

Table 1: $\quad$ Motives for investing in eco-innovation.

\begin{tabular}{|l|c|c|c|}
\hline \multirow{2}{*}{ MOTIVES } & \multicolumn{3}{c|}{ CHAIN } \\
\cline { 2 - 4 } & A & B & C \\
\hline Potential cost savings & $\checkmark$ & $\checkmark$ & $\checkmark$ \\
\hline $\begin{array}{l}\text { Improved image and increased } \\
\text { market share }\end{array}$ & $\checkmark$ & $\checkmark$ & $\checkmark$ \\
\hline Competitive advantage acquisition & $\checkmark$ & $\checkmark$ & $\checkmark$ \\
\hline Intrinsic motivation & & $\checkmark$ & $\checkmark$ \\
\hline Increased employee motivation & & $\checkmark$ & $\checkmark$ \\
\hline Requests from guests & & $\checkmark$ & $\checkmark$ \\
\hline Advice from other professionals & & & \\
\hline Others & $\checkmark$ & & \\
\hline
\end{tabular}

Table 1 shows that all the hotel chains invest in eco-innovations motivated by "Potential cost savings", "Improved image and increased market share" and "competitive advantage acquisition". Chain B and C also highlighted the alternatives: "Intrinsic motivation", "Increased motivation of employees" and "Requests from guests". "Advice from other professionals" was not reported by any of the companies.

When it came to "Others", Chain A pointed that one reason is "Increasing stakeholder awareness of the importance of the environmental issue" and "Satisfying investors, guests, colleagues and the community."

All the respondents said that investment in eco-innovation is motivated, among other things, as a competitive strategy. However, by paying more attention to the other indicators, such as "Potential cost savings" and "Improved image and increased market share", it is clear that these factors can also generate a competitive advantage and may be part of a competitive strategy approach. Furthermore, the alternative stated by Chain A, "Satisfying investors, guests, the community and colleagues," may be related to a competitive strategy, since, according to Harrison and Enz [17], the relationship with stakeholders can be a source of competitive advantage.

If the respondents said that one of the reasons for their investments in ecoinnovation was to gain competitive advantage, they were asked to identify the competitive advantages that eco-innovation brought to their companies. 
Table 2: Competitive advantages of investing in eco-innovation.

\begin{tabular}{|l|c|c|c|}
\hline \multirow{2}{*}{ COMPETITIVE ADVANTAGE } & \multicolumn{3}{|c|}{ CHAIN } \\
\cline { 2 - 4 } & A & B & C \\
\hline Improved efficiency & $\checkmark$ & $\checkmark$ & $\checkmark$ \\
\hline Waste reduction & $\checkmark$ & $\checkmark$ & $\checkmark$ \\
\hline Increased profitability & $\checkmark$ & $\checkmark$ & $\checkmark$ \\
\hline Increased productivity & $\checkmark$ & $\checkmark$ & $\checkmark$ \\
\hline Improved quality & $\checkmark$ & $\checkmark$ & $\checkmark$ \\
\hline Cost reduction & $\checkmark$ & $\checkmark$ & $\checkmark$ \\
\hline Others & $\checkmark$ & $\checkmark$ & \\
\hline
\end{tabular}

Table 2 shows, from the respondents' point of view, that all the indicators offered to respond to this question bring competitive advantages to the organizations. When it came to "Others", Chain A also highlighted "Market recognition" as a competitive advantage. Chain B pointed out that one of the competitive advantages gained from investing in eco-innovation was the "Satisfaction of investors, guests, colleagues and the community."

Some of these advantages are considered sufficient reason to invest in this kind of innovation, and it can be determined from the responses that eco-innovations can generate different competitive advantages. This conclusion reaffirms the importance of the relationship between these two phenomena.

The next question inquired as to whether the respondents believe there is a relationship between eco-innovation and competitive strategies in their companies. All the professionals answered in the affirmative.

Therefore, based on the responses, eco-innovations can be viewed as generators of competitive advantages for hotel chains. At the same time, the possibility of acquiring competitive advantages also encourages hoteliers to invest in this kind of innovation, generating a systemic relationship. This relationship is clearly illustrated in Figure 1.

For a more in-depth understanding of this relationship, the interviewees were asked to explain how it occurs. Chain A explained that:

[We] have always been concerned about the environment. Some of our hotels are located in areas of great scenic beauty and we wished to preserve these sites. We are involved in several fauna and flora conservation programs [...]. Our sustainability program, at first, did not have a competitive objective, [...] but it has generated cost savings and received awards in recognition of our results and initiatives. [...] The competitive strategies of [...] are drawn up by our SLIM (strategic program), which is headed by our CEO. The Department of Corporate Social Responsibility is dependent on SLIM. We have some autonomy, but our actions must be linked to the strategic direction of the company. The Director of Corporate Social Responsibility and Sustainability reports directly to the CEO [...]. 


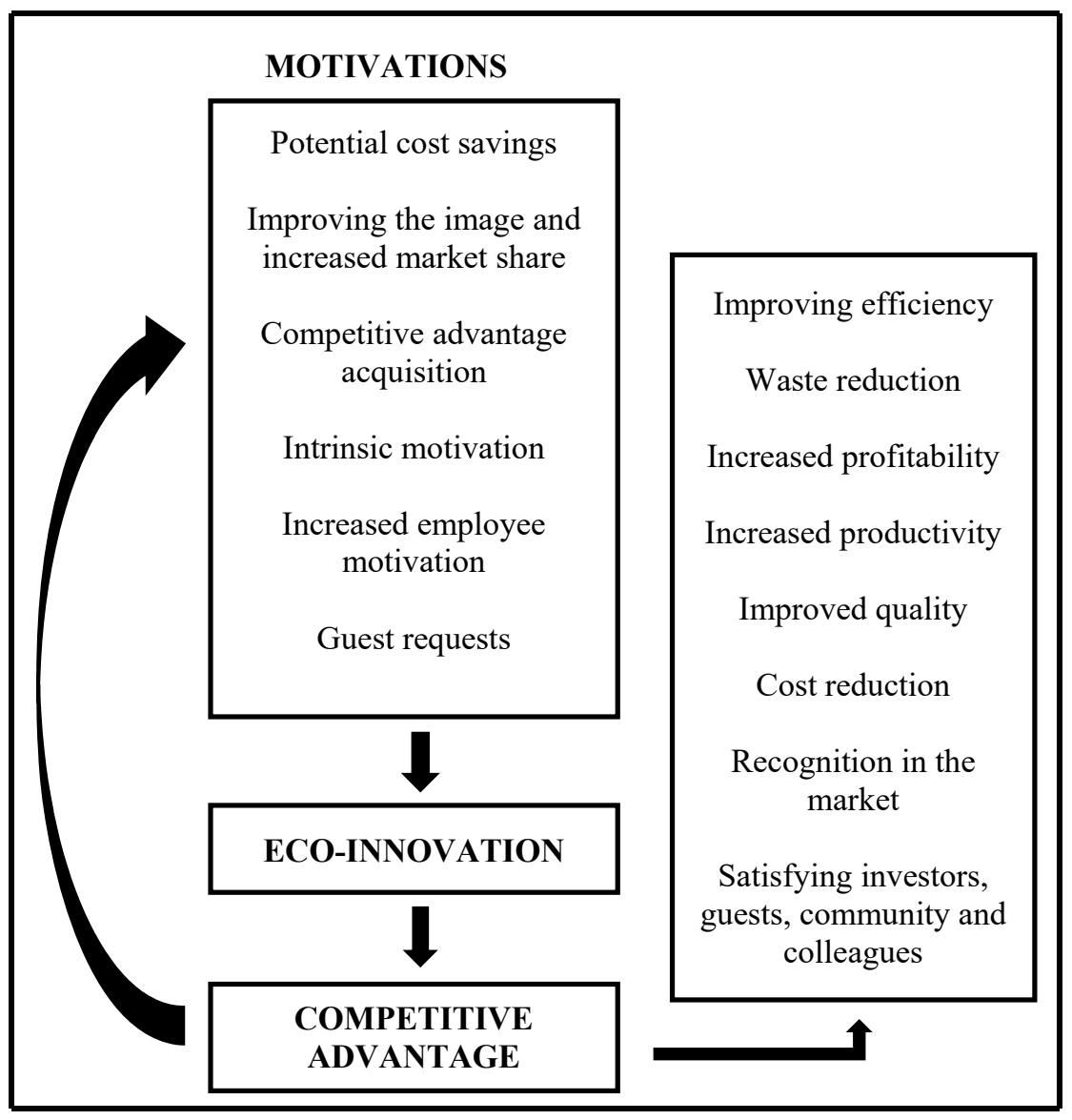

Figure 1: Relationship between eco-innovation and competitive strategies based on the reasons for investing in these innovations.

Chain B:

We were the first hotel group to create an environmental sustainability program, even before environmentalism became a buzzword. At first, we had few hotels in Canada and only thought of consuming natural resources more consciously. We were closely engaged with the environment. Other hotels became interested in the program and bought the idea; they have adopted some initiatives and innovations. Our green philosophy has become a core value for the company. Over time, we realized that sustainable initiatives were generating a differentiation. The initiatives brought our company market recognition and cost savings. We saw then that our sustainability program was a competitive advantage, and could be used with one of our competitive strategies [...]. Today, our sustainability strategy is linked to the brand strategy. Our competitive strategies are not autonomous, but fully 
interconnected and dependent on our values. We are committed to providing a service that satisfies our demand, helping the client to connect to the essence of the destination, but at the same time, we are committed to the ecosystem and the environment. Therefore, our competitive strategies are developed in these two directions. [...] For us, the two strategies are interlinked and one cannot be successful without the other.

Chain C:

Our sustainability program has always had a competitive aim. We believe there are two main ways in which we can gain a competitive advantage. One is operating a more efficient hotel, gaining an advantage for current and future owners. The second is to be sensitive to customer needs, even if it is on the carbon footprint of a large customer base or the request for a guest to reduce their emissions. [...] There is a direct relationship between competitive strategies and sustainable innovation. As I mentioned, we can focus on reducing costs and improving our response to customers, especially for the new generation. That enables us to be more competitive and gain a bigger market share.

The responses show that eco-innovation was not developed as a competitive strategy in the case of Chain A and B. however, it became a competitive strategy as soon as the company managers realized that a sustainability program also generated a competitive advantage for their hotel groups.

Unlike the previous two chains, Chain $\mathrm{C}$ stated that it always understood that the eco-innovations developed by the company were part of the organizational competitive strategy, because they could benefit the current/future owners and customers of the company.

These results showed that, based on the evolution of the relationship between eco-innovation and competitive strategies, the three cases fit into two types of chains. Type 1 is those whose eco-innovations were implemented by moral issues and the values held by the organization, but as time went by came to be seen as a competitive strategy. This type of case can be seen in Chains A and B. There is also Type 2, where eco-innovation has always been related to the competitive strategies of the company, as was the case of Chain C. These two types of chain are illustrated in Figure 2.

Regarding the type of relationship, during the interviews, the respondent for Chain A indicated that the Department of Corporate Social Responsibility depends on the Strategic Department of the company (SLIM). Even if the Department has some autonomy, according to the respondent, the actions of this division are linked to the strategic direction of Chain A. Therefore, the statements made during the interview show that there is a certain relationship of dependency. The ecoinnovations must be linked to the strategies established by the company. In this case, a parasitic relationship was identified. According to Saviotti [1], this type of relationship occurs when one party clearly benefits from the other. In the case 


\section{TYPE 1 - NO INITIAL COMPETITIVE PURPOSE}

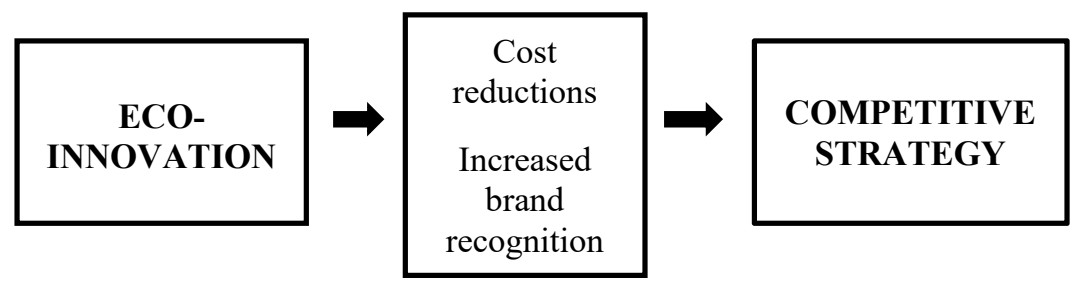

TYPE 2 - INITIAL COMPETITIVE PURPOSE

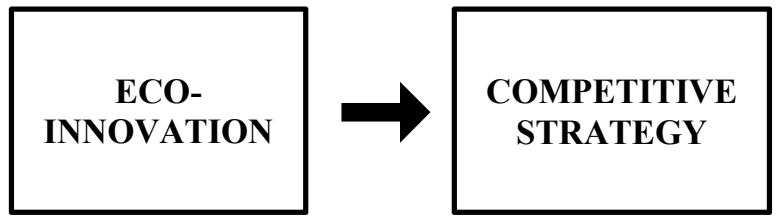

Figure 2: Evolution of the relationship between eco-innovation and competitive strategies.

of Chain A, the Department of Corporate Social Responsibility benefits from the strategies previously defined by the Strategic Department of the company.

Regarding Chain B, according to the interviewee, the Green Partnership Program is linked to the competitive strategies of the company. However, one is not dependent on the other, merely supportive. In this case, the relationship would be characterized as mutualistic, when both parties benefit from the exchange, according to Saviotti [1].

From the fragment of the interview with the representative of Chain $\mathrm{C}$, a direct link between both was revealed, constituting, as in Chain B, a mutualistic relationship.

Therefore, it was found that the three case studies fit two types of hotel chains. In the first case, the relationship between eco-innovation and competitive strategy is a mutualistic one, as in Chain B and C. The second type of hotel chain is one in which there is a dependency relationship between these two factors, as in Chain A. In this case, the eco-innovations are linked to the company's strategic direction. It is noteworthy here that this result contradicts in part one of the hypotheses of this study. Initially, it was believed that the relationship between eco-innovation 
and competitive strategies found in these cases would only be one of mutualism. However, the relationships have been shown to be different.

From all the data collected, it can be concluded that eco-innovations can generate competitive advantages for global hotel chains. At the same time, the possibility of acquiring competitive advantages also encourages hoteliers to invest in this kind of innovation. The initial motivation to invest in eco-innovation is not always related to the competitive strategies of the company. In some cases, the eco-innovations are initially implemented for moral reasons and because of the values of the organization. However, once the organization becomes aware of the competitive advantages to be gained, eco-innovation becomes part of the competitive strategy of the hotel chain. There is a relationship between ecoinnovation and competitive strategy. Sometimes, it can be one of parasitism; at other times, one of mutualism. It would depend on the company's approach to sustainable issues. Based on these results, a conceptual model has been constructed (as shown in Figure 3).

\section{Conclusion}

The study sought to comprehend the relationship between eco-innovation and competitive strategies in global hotel chains. The data indicated that there is a direct relationship between eco-innovation and competitive strategies in global hotel chains. However, this relationship differs according to the case study in question. The relationship can be classified according to the biological conceptions of the relationship [1], mainly parasitism and mutualism. Therefore, a conceptual model was constructed, presenting the variables related to these two phenomena.

There are some limitations to the study. The paper addresses only three global hotel chains and does not take into account the culture of each company, noting that the organizational culture and the headquarter country location can interfere with how they understand and value environmental sustainability, competitive strategies and their relationship. Therefore, the findings cannot be generalized for all hotel chains or even independent hotels, which have a different reality and face different challenges regarding eco-innovation.

This study is part of a larger investigation focusing on the relationship between these two phenomena. It was not intended to be conclusive, but rather to encourage other studies related to this theme. Suggestions for further investigations include paying greater attention to different case studies in other global hotel chains. Studies could be conducted on hotel chains in different continents, which could be compared to verify whether there are differences in the relationship, considering cultural issues, as mentioned above. The study could be replicated for independent hotels, to gauge to what extent these types of company differ from each other. 


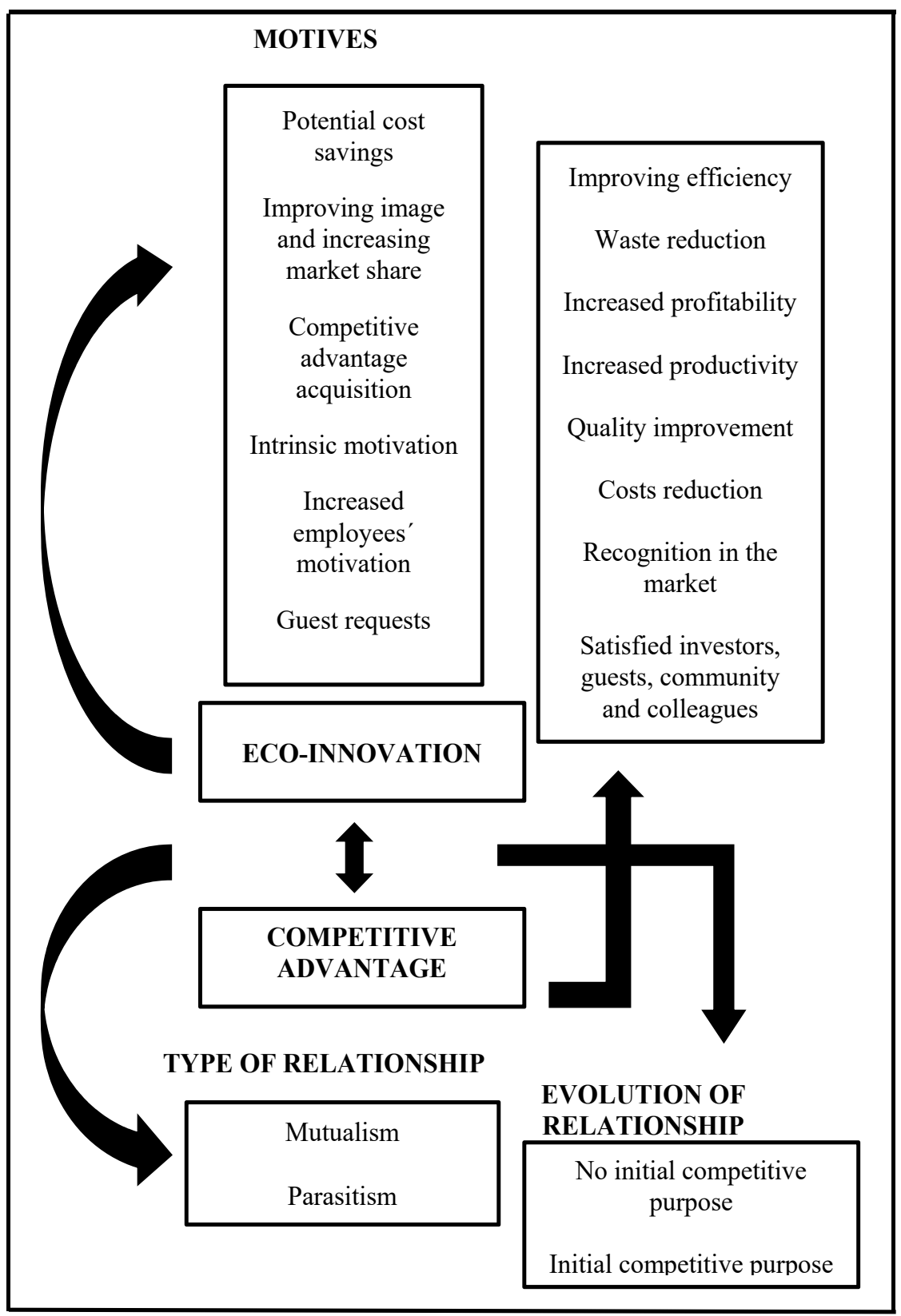

Figure 3: Conceptual model for the relationship between eco-innovation and competitive strategies. 


\section{References}

[1] Saviotti, P. P. Co-evolution of technical, environmental and social system. Weber, M., Hemmelskamp, J. (Ed). Towards environmental innovation system. Berlin: Springer, 2010.

[2] Kirk, D. Environmental management for hotels: a student's handbook. Oxford: Butterworth-Heinemann, 1996.

[3] Bohdanowicz, P. Environmental awareness and initiatives in the Swedish and Polish hotel industries - survey results International. Journal of Hospitality Management, 25(4), pp.662-682, 2006. Online. http://mba.rea.ru/hotel/Teachers/SampleArticles/5.pdf.

[4] Bohdanowicz, P.; Martinac, I. Attitudes towards sustainability in chain hotels - Results of a European survey. 2003. Online. http://storage.globalcitizen.net/data/topic/knowledge/uploads/2012022312 648705.pdf.

[5] Sloan, P., Legrand, W., Chen, J. Sustainability in the hospitality industry. Principles of sustainable operations. 2.ed. New York: Routledge, 2013.

[6] Viera, E.V. Desperdício em hotelaria: soluções para evitar. Caxias do Sul: EDUCS, 2004.

[7] Carrillo-Hermosilla, J., González, P. R., Könöla, T. Ecco-Innovation. When sustainability and competitiveness shake hands. London: Pallgrave Macmillan, 2009.

[8] Netemeyer, R.G., Bearden, W.O., Sharma, S. Scaling procedures: issues and applications. Thousand Oaks: Sage Publications, 2003.

[9] James, P. The Sustainability Circle: a new tool for product development and design. Journal of Sustainable Product Design, 2, pp. 52-57, 1997.

[10] Andersen, M.M. Eco-innovation - towards a taxonomy and a theory. DRUID Conference, 2008. Online. www2.druid.dk/conferences/ viewpaper.php?id $=3150 \& c f=29.2015$.

[11] Porter, M., Van der Linde, C. Green and competitive: ending the stalemate. Harvard Business Review, 1995. Online. www.uvm.edu/ gflomenh/ ENRG-POL-PA395/readings/Porter_Linde.pdf.

[12] Shrivastava, P. Environmental technologies and competitive advantage. Strategic Management Journal, 16, pp. 183-200, 1995.

[13] Porter, M., Van Der Linde, C. Toward a new conception of the environmental-competitiveness relationship. Journal of Economic Perspectives, 9(4), pp. 97-118, 1995.

[14] Porter, M., Van der Linde, C. Verde e competitivo: acabando com o impasse. Porter, M. E. Competição = On competition: estratégias competitivas essenciais. 10.ed. Trad. Afonso Celso da Cunha Serra. Rio de Janeiro: Campus, 1999.

[15] Porter, M. Vantagem competitiva: criando e sustentando um desempenho superior. Rio de Janeiro: Campus, 1990. 
[16] Eidat, Y., Kelly, A., Roche, F., Eydat, H. Green and competitive? An empirical test of the mediating role of environmental innovation strategy. Journal of World Business, 43(2), pp. 131-145, 2008.

[17] Harrison, J. S., Enz, C. A. Hospitality strategic management. Hoboke, New Jersey: John Wiley \& Sons, 2005. 